\title{
Physiological effects of different recruitment maneuvers in a pig model of ARDS
}

Feiping Xia, Chun Pan, Lihui Wang, Ling Liu, Songqiao Liu, Fengmei Guo, Yi Yang and Yingzi Huang*

\begin{abstract}
Background: In acute respiratory distress syndrome (ARDS), lung recruitment maneuvers can recruit collapsed alveoli in gravity-dependent lung regions, improving the homogeneity of ventilation distribution. This study used electrical impedance tomography to investigate the physiological effects of different recruitment maneuvers for alveolar recruitment in a pig model of ARDS.
\end{abstract}

Methods: ARDS was induced in ten healthy male pigs with repeated bronchoalveolar lavage until the ratio of arterial partial pressure of oxygen $\left(\mathrm{PaO}_{2}\right)$ of fraction of inspired oxygen (P/F) was $<100 \mathrm{mmHg}$ and remained stable for $30 \mathrm{~min}\left(\mathrm{~T}_{\mathrm{ARDS}}\right)$. ARDS pigs underwent three sequential recruitment maneuvers, including sustained inflation, increments of positive end-expiratory pressure (PEEP), and pressure-controlled ventilation (PCV) applied in random order, with 30 mins at a PEEP of $5 \mathrm{cmH}_{2} \mathrm{O}$ between maneuvers. Respiratory mechanics, hemodynamics, arterial blood gas, and electrical impedance tomography were recorded at baseline, $T_{\text {ARDS }}$, and before and after each recruitment maneuver.

Results: In all ten pigs, ARDS was successfully induced with a mean $2.8 \pm 1.03 \mathrm{~L}$ bronchoalveolar lavages. $\mathrm{PaO}_{2}, \mathrm{P} / \mathrm{F}$, and compliance were significantly improved after recruitment with sustained inflation, increments of PEEP or PCV (all $p<0.05)$, and there were no significant differences between maneuvers. Global inhomogeneity index significantly decreased after recruitment with sustained inflation, increments of PEEP, or PCV. There were no significant differences in global inhomogeneity before or after recruitment with the different maneuvers. The decrease in global inhomogeneity index $(\Delta G \mid)$ was significantly greater after recruitment with increments of PEEP compared to sustained inflation $(p=0.023)$, but there was no significant difference in $\Delta \mathrm{Gl}$ between increments of PEEP and PCV or between sustained inflation and PCV.

Conclusion: Sustained inflation, increments of PEEP, and PCV increased oxygenation, and regional and global compliance of the respiratory system, and decreased inhomogeneous gas distribution in ARDS pigs. Increments of PEEP significantly improved inhomogeneity of the lung compared to sustained inflation, while there was no difference between increments of PEEP and PCV or between sustained inflation and PCV.

Keywords: Electrical impedance tomography, Global inhomogeneity, Acute respiratory distress syndrome

\footnotetext{
*Correspondence: yz_huang@126.com

Department of Critical Care Medicine, Zhongda Hospital, School of Medicine, Southeast University, No.87, Dingjiaqiao Road, Gulou District, Nanjing 210009, Jiangsu, China
}

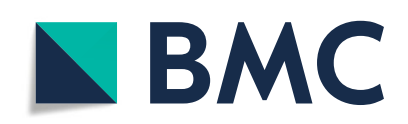

(c) The Author(s). 2020 Open Access This article is licensed under a Creative Commons Attribution 4.0 International License, which permits use, sharing, adaptation, distribution and reproduction in any medium or format, as long as you give appropriate credit to the original author(s) and the source, provide a link to the Creative Commons licence, and indicate if changes were made. The images or other third party material in this article are included in the article's Creative Commons licence, unless indicated otherwise in a credit line to the material. If material is not included in the article's Creative Commons licence and your intended use is not permitted by statutory regulation or exceeds the permitted use, you will need to obtain permission directly from the copyright holder. To view a copy of this licence, visit http://creativecommons.org/licenses/by/4.0/ The Creative Commons Public Domain Dedication waiver (http://creativecommons.org/publicdomain/zero/1.0/) applies to the data made available in this article, unless otherwise stated in a credit line to the data. 


\section{Background}

Acute respiratory distress syndrome (ARDS) is a clinical syndrome characterized by a decrease in functional lung size [1]. The pathophysiology of ARDS includes diffuse alveolar collapse [2] and acute exudative lesions distributed in a gravitationally dependent gradient [3]. Although this disease was first defined almost 50 years ago, the hospital mortality rate for patients with severe ARDS remains high, estimated at $46 \%$ [4].

Lung recruitment maneuvers, including sustained inflation, increments of positive end-expiratory pressure (PEEP), and pressure-controlled ventilation (PCV), can improve oxygenation and increase respiratory system compliance in patients with ARDS. Recruitment maneuvers can recruit collapsed alveoli in gravity-dependent lung regions and improve the homogeneity of ventilation distribution, but may cause alveolar overdistention and lead to ventilatorassociated lung injury in non-dependent regions [5]. A randomized controlled trial showed that sustained inflation and PCV improved the arterial partial pressure of oxygen $\left(\mathrm{PaO}_{2}\right) /$ fraction of inspired oxygen $\left(\mathrm{FiO}_{2}\right)(\mathrm{P} / \mathrm{F})$ in 40 patients with $\mathrm{ARDS}$, and the $\mathrm{P} / \mathrm{F}$ was significantly increased after PCV compared to sustained inflation [6]. However, dynamic regional information on changes in lung ventilation after recruitment maneuvers has not been reported.

Recruitment and overdistention during lung recruitment have been evaluated by chest X-ray, computed tomography, and lung ultrasound. Electrical impedance tomography (EIT) is a non-invasive, radiation-free technique that can be used for bedside monitoring of lung tissue aeration during breathing. EIT allows semi-continuous, realtime measurement of changes in electrical resistivity within lung tissue and provides information on regional ventilation distributions [7, 8]. Domenighetti [9] reported that EIT can be used to measure impedance changes and assess regional ventilation distribution during tidal breathing. The EIT-based global inhomogeneity index has been developed as a tool to quantify tidal volume (Vt) distribution within the lung [10].

Previous research has focused on the effect of recruitment maneuvers on gas exchange and hemodynamics. Literature describing the influence of recruitment maneuvers on global inhomogeneity and regional ventilation distribution is scarce. This study used EIT to investigate the physiological effects of different recruitment maneuvers that achieve the same maximum pressure for alveolar recruitment in a porcine model of ARDS. Findings may inform clinical decision-making around recruitment maneuvers while minimizing the risk of barotrauma in individuals with ARDS.

\section{Methods}

The protocol for this study was approved by the Science and Technological Committee and the Animal Use and
Care Committee of the University School of Medicine, Nanjing, China. Domestic pigs (Sus scrofa domesticus) were purchased from a local farmer (Qinglongshan animal breeding farm, JiangShu, China). Animal experiments were performed in accordance with the Guidance for the Care and Use of Laboratory Animals [11].

\section{Animal preparation}

Pigs were housed on straw in a cage and fed with a standard diet [12]. Prior to the study, the animals were fasted overnight. Ten healthy male pigs (body weight $50.3 \pm 1.5 \mathrm{~kg}$ ) were anesthetized with an intramuscular injection of ketamine hydrochloride $(3 \mathrm{mg} / \mathrm{kg})$, atropine $(2 \mathrm{mg} / \mathrm{kg})$ and fentanyl citrate $(2 \mathrm{mg} / \mathrm{kg})$ and an intravenous infusion of propofol (1-2 mg/kg.h), fentanyl citrate $(0.5-1 \mu \mathrm{g} / \mathrm{kg} \cdot \mathrm{h})$, midazolam $(0.1 \mathrm{mg} / \mathrm{kg} \cdot \mathrm{h})$, and atracurium $(0.4 \mathrm{mg} / \mathrm{kg} \cdot \mathrm{h})$ and placed in the supine position on a thermo-regulated operating table. During surgery, pigs received balanced electrolyte solution $(5 \mathrm{ml} / \mathrm{kg} / \mathrm{h})$, pigs' body temperature was maintained at $37.5^{\circ} \mathrm{C}$, and pigs' mean arterial pressure (MAP) was maintained $>60$ $\mathrm{mmHg}$ with rapid infusions of $0.9 \%$ saline $(20 \mathrm{ml} / \mathrm{kg})$, as needed.

Following anesthesia, tracheotomy was performed, and pigs were mechanically ventilated (Servo-i ventilator, Solna, Sweden) using volume-control mode at a Vt of 6 $\mathrm{mL} / \mathrm{kg}$, a respiratory rate of 30 breaths $/ \mathrm{min}, \mathrm{FiO}_{2}$ of 1.0 , a inspiration-to-expiration time ratio (I:E) of $1: 2$, and PEEP of $5 \mathrm{cmH}_{2} \mathrm{O}$. Arterial blood samples were collected using a thermistor-tipped Pulse Contour Cardiac Output (PiCCO) catheter (Pulsion Medical System, Munich, Germany) inserted in the right femoral artery. Central venous pressure (CVP) and pulmonary arterial wedge pressure (PAWP) were measured using a Swan-Ganz catheter (Arrow International, Reading, PA, USA) inserted in the internal jugular vein. Cardiac output was measured with the Swan-Ganz catheter, and MAP was monitored with the PiCCO catheter.

\section{Experiment protocol}

Baseline measurements $\left(\mathrm{T}_{\text {Baseline }}\right)$ were made after pigs had stabilized for $30 \mathrm{~min}$. Subsequently, a pig model of ARDS was established using bilateral lung lavage with isotonic saline $\left(30 \mathrm{ml} / \mathrm{kg} ; 38^{\circ} \mathrm{C}\right)$ infused through a funnel. Negative pressure was applied to the proximal portion of an endotracheal tube to remove excessive fluid. Alveolar lavage was repeated every $10 \mathrm{~min}$ until the $\mathrm{P} / \mathrm{F}$ ratio decreased to less than $100 \mathrm{mmHg}$ and remained stable for $30 \mathrm{~min}\left(\mathrm{~T}_{\mathrm{ARDS}}\right)$; then, $\mathrm{FiO}_{2}$ was set at 0.4.

ARDS pigs underwent three sequential recruitment maneuvers, including sustained inflation, increments of PEEP and PCV applied in random order according to a random number table, with 30 mins at a PEEP of 5 $\mathrm{cmH}_{2} \mathrm{O}$ between maneuvers (Fig. 1). Circulatory and 


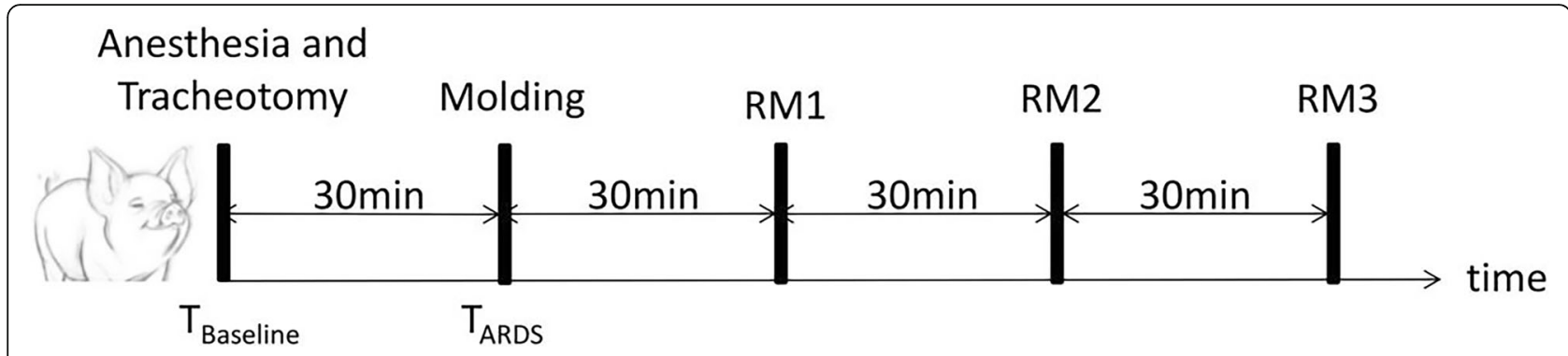

Fig. 1 Flowchart of study design. ARDS pigs underwent three sequential recruitment maneuvers applied in random order according to a random number table, with 30 mins at a PEEP of $5 \mathrm{cmH}_{2} \mathrm{O}$ between maneuvers. Respiratory mechanics, hemodynamic parameters, arterial blood gas and EIT were recorded at $T_{\text {Baseline, }} T_{\text {ARDS }}$, and before and after each recruitment maneuver

lung mechanics recovered in $30 \mathrm{~min}$ after recruitment maneuvers [13] and a PEEP of $5 \mathrm{cmH}_{2} \mathrm{O}$ represented physiologic PEEP. Sustained inflation was performed using continuous positive airway pressure (CPAP) held at $40 \mathrm{cmH}_{2} \mathrm{O}$ for $40 \mathrm{~s}$ [14]. For increments of PEEP, PEEP was increased from $5 \mathrm{cmH}_{2} \mathrm{O}$ to a maximum of 40 $\mathrm{cmH}_{2} \mathrm{O}$ in $5 \mathrm{cmH}_{2} \mathrm{O}$ increments, with each increment lasting $30 \mathrm{~s}$, and retuned to $5 \mathrm{cmH}_{2} \mathrm{O}$ in the reverse process. For $\mathrm{PCV}$, peak pressure was $40 \mathrm{cmH}_{2} \mathrm{O}$, inspiratory to expiratory ratio was $1: 2$, and PEEP was 20 $\mathrm{cmH}_{2} \mathrm{O}$ for $2 \mathrm{~min}$. For increments of PEEP and PCV, respiratory rate was set to 30 breaths/min. Respiratory mechanics, hemodynamic parameters, arterial blood gas, and EIT were recorded at $\mathrm{T}_{\text {Baseline, }} \mathrm{T}_{\mathrm{ARDS}}$, and before and after each recruitment maneuver. MAP, CVP, and PAWP were monitored using calibrated pressure transducers. Blood gases were evaluated with an automated blood gas analyser (Nova M; Nova Biomedical, Waltham, MA, USA).

\section{EIT measurements and analysis}

EIT measurements (PulmoVista 500; Dräger Medical $\mathrm{GmbH}$, Lübeck, Germany) were performed for $3 \mathrm{~min}$ each at $\mathrm{T}_{\text {Baseline, }} \mathrm{T}_{\mathrm{ARDS}}$, and before and after each recruitment maneuver as previously described [15]. EIT data were generated by applying small alternate electrical currents through 16 electrodes located equidistant apart on a belt positioned around the pigs' thorax, $5 \mathrm{~cm}$ above the xyphoid process. A reference electrocardiogram (ECG) electrode was positioned on the abdomen. Current applications and voltage measurements were automatically selected to be compatible with the image reconstruction algorithm. The images were continuously recorded and reconstructed at $40 \mathrm{~Hz}$ (Draeger EIT Data Analysis Tool 6.1).

Four regions of interests (ROI) of the same size and shape consisting of contiguous pixels were identified within EIT images obtained during tidal breathing. A cross section of the lung (ventral to dorsal) was divided into four equal parts, namely ROI1, ROI2, ROI3 and ROI4. The upper quarter corresponded to ROI1 and the second quarter from the top to the bottom corresponded to ROI2. The third quarter and the fourth quarter respectively corresponded to ROI3 and ROI4. ROI1 and 2 correspond to non-dependent regions and ROI3 and 4 correspond to gravity-dependent regions (Additional file 1) [16]. For each breathing cycle, the impedance change of the lung was calculated as the impedance difference between end-inspiration and end-expiration of the transverse section image. $\Delta \mathrm{Z}_{\mathrm{ROI}}$ was defined as the impedance change of an ROI [5]. EIT-estimated regional compliance was calculated as $\Delta \mathrm{Z}_{\mathrm{ROI}}$ /driving pressure [17]. Tidal volume distribution within the lung was quantified using the global inhomogeneity index, as previously described [18], and analysis of the global inhomogeneity index was performed using customized software developed by Zhao (evaluation_perfusion.exe). For each breathing cycle, the median value of a tidal image, in which each pixel represented the difference in impedance between end-inspiration and end-expiration, was calculated. The absolute difference between the median value and every pixel value was summed to indicate the variation in the Vt distribution. The global inhomogeneity index was adjusted by normalization to the sum of the impedance values. A smaller global inhomogeneity index represented a more homogeneous distribution, and a larger global inhomogeneity index indicated a more inhomogeneous ventilation. The decrease in global inhomogeneity index $(\Delta \mathrm{GI})$ with each recruitment maneuver was calculated as the difference in global inhomogeneity index before and after recruitment.

General anesthesia was maintained throughout the study. After completion of the experiments, the animals were in deep anesthesia with propofol $(2 \mathrm{mg} / \mathrm{kg} \cdot \mathrm{h})$, fentanyl citrate $(1 \mu \mathrm{g} / \mathrm{kg} \cdot \mathrm{h})$, midazolam $(0.1 \mathrm{mg} / \mathrm{kg} \cdot \mathrm{h})$, and atracurium $(0.4 \mathrm{mg} / \mathrm{kg} \cdot \mathrm{h})$. They were euthanized by a bolus injection of thiopental $(0.1 \mathrm{~g} / \mathrm{kg})$ intravenously.

\section{Statistical analyses}

Statistical analyses were performed using SPSS v20 (Chicago, IL, USA). Differences in global inhomogeneity and changes in global and regional end-expiratory lung 
impedance among different recruitment maneuvers were investigated. Comparisons were made between values obtained before and after each recruitment maneuver. For non-normally distributed data, results are expressed as median and interquartile range, and comparisons were made with the Wilcoxon rank test. For data that was normally distributed, results are expressed as mean and standard deviation, and comparisons were made with paired samples $\mathrm{t}$ tests and Bonferroni correction. $p<0.05$ was considered statistically significant.

\section{Results}

In all ten pigs, ARDS was successfully induced with a mean $2.8 \pm 1.03 \mathrm{~L} \quad(2800 \pm 1032.80 \mathrm{ml})$ bronchoalveolar lavages. Mean $\mathrm{P} / \mathrm{F}$ was significantly decreased after the final lavage $(81.69 \pm 55.79 \mathrm{mmHg})$ compared to baseline $(362.48 \pm 117.38 \mathrm{mmHg})$.

There were no significant differences in hemodynamic parameters after recruitment with the different maneuvers (Table 1). No animals died during the experiments.

$\mathrm{PaO}_{2}$, arterial oxygen saturation, and $\mathrm{P} / \mathrm{F}$ were significantly improved after recruitment with sustained inflation, increments of PEEP or PCV (all $p<0.05$ ), and there were no significant differences between maneuvers. The recruitment maneuvers had no effect on $\mathrm{PaCO}_{2}$ or $\mathrm{pH}$ (Table 1).

Overall respiratory system compliance was significantly increased after recruitment with sustained inflation, increments of PEEP, or PCV $(p<0.05)$ (Table 1). The recruitment maneuvers had no significant effect on compliance in non-gravity-dependent lung regions. Compliance was significantly increased in gravitydependent lung regions after lung recruitment with increments of PEEP or PCV (preIP $0.74 \pm 0.37 \mathrm{au} /$ $\mathrm{cmH}_{2} \mathrm{O}$ vs. postIP $2.51 \pm 1.80 \mathrm{au} / \mathrm{cmH}_{2} \mathrm{O}, \quad p=0.025$; prePCV $0.75 \pm 0.36 \mathrm{au} / \mathrm{cmH}_{2} \mathrm{O}$ vs. postPCV $2.78 \pm 1.65$ $\mathrm{au} / \mathrm{cmH}_{2} \mathrm{O}, p=0.012$ ), but there were no significant differences in compliance between maneuvers (Fig. 2).

Global inhomogeneity index was significantly decreased after recruitment with sustained inflation, increments of PEEP, or PCV (preSI $0.55 \pm 0.14 \mathrm{u}$ vs. postSI $0.42 \pm 0.040$; preIP $0.62 \pm 0.19 \mathrm{u}$ vs. postIP $0.42 \pm 0.07 \mathrm{u}$; prePCV $0.60 \pm 0.09$ u vs. postPCV $0.4431 \pm 0.05 \mathrm{u}$; all $p<$ 0.001 ) (Fig. 3). The $\Delta$ GI was significantly greater after recruitment with increments of PEEP compared to sustained inflation $(p=0.023)$, but there was no difference in $\triangle$ GI between increments of PEEP and PCV or between sustained inflation and PCV (Fig. 4).

\section{Discussion}

This study used EIT to investigate the physiological effects of different recruitment maneuvers that achieve the same maximum pressure when held for different time spans, including sustained inflation, increments of PEEP and $\mathrm{PCV}$, for alveolar recruitment in a pig model of ARDS. Findings showed that these recruitment maneuvers increased oxygenation and compliance in overall and gravity-dependent lung regions, and decreased inhomogeneous gas distribution in the ARDS lung, with no adverse effects on hemodynamics immediately after the maneuver. In a previous study [19], recruitment maneuvers transiently but profoundly depressed cardiac output in three models of acute lung injury. These results imply that a lung recruiting maneuver should be applied with caution, especially when using sustained inflation in the setting of pneumonia.

Table 1 Hemodynamic and oxygenation parameters before and after recruitment maneuvers

\begin{tabular}{|c|c|c|c|c|c|c|c|c|c|}
\hline & \multicolumn{3}{|l|}{ SI } & \multicolumn{3}{|l|}{ IP } & \multicolumn{3}{|l|}{ PCV } \\
\hline & Before & After & $p$ & Before & After & $p$ & Before & After & $p$ \\
\hline HR (BPM) & $89.1 \pm 25.32$ & $97.5 \pm 31.17$ & 0.517 & $90.4 \pm 39.40$ & $96.9 \pm 46.84$ & 0.950 & $93.8 \pm 38.44$ & $94.1 \pm 41.04$ & 0.987 \\
\hline MAP $(\mathrm{mmHg})$ & $102.1 \pm 23.14$ & $92.7 \pm 17.71$ & 0.321 & $109.2 \pm 19.00$ & $96.8 \pm 23.93$ & 0.455 & $109.1 \pm 20.26$ & $96.6 \pm 23.53$ & 0.219 \\
\hline CVP (mmHg) & $7.62 \pm 3.37$ & $8.81 \pm 3.12$ & 0.420 & $7.45 \pm 2.91$ & $9.10 \pm 4.72$ & 0.523 & $7.42 \pm 2.67$ & $9.46 \pm 3.41$ & 0.161 \\
\hline PAWP (mmHg) & $8.81 \pm 4.94$ & $10.72 \pm 4.40$ & 0.376 & $9.34 \pm 4.08$ & $11.62 \pm 4.88$ & 0.349 & $9.17 \pm 3.67$ & $10.83 \pm 4.59$ & 0.372 \\
\hline $\mathrm{CO}(\mathrm{L} / \mathrm{min})$ & $4.74 \pm 1.55$ & $4.45 \pm 1.35$ & 0.664 & $4.74 \pm 2.11$ & $4.46 \pm 1.63$ & 0.733 & $4.53 \pm 1.67$ & $4.48 \pm 1.63$ & 0.945 \\
\hline $\mathrm{pH}$ & $7.28 \pm 0.12$ & $7.29 \pm 0.12$ & 0.95 & $7.27 \pm 0.13$ & $7.30 \pm 0.12$ & 0.627 & $7.27 \pm 0.12$ & $7.31 \pm 0.12$ & 0.468 \\
\hline $\mathrm{PaCO}_{2}(\mathrm{mmHg})$ & $52.56 \pm 13.82$ & $48.24 \pm 13.20$ & 0.484 & $55.82 \pm 17.49$ & $45.94 \pm 13.82$ & 0.206 & $56.2 \pm 16.15$ & $46.09 \pm 13.70$ & 0.568 \\
\hline $\mathrm{PaO}_{2}(\mathrm{mmHg})$ & $81.62 \pm 22.36$ & $145.83 \pm 26.86^{a}$ & 0.000 & $78.22 \pm 24.28$ & $167.98 \pm 36.85^{a}$ & 0.000 & $77.54 \pm 24.69$ & $155.83 \pm 50.85^{a}$ & 0.000 \\
\hline $\mathrm{SaO}_{2}$ & $86.77 \pm 8.28$ & $96.46 \pm 2.05^{\mathrm{a}}$ & 0.002 & $84.91 \pm 8.25$ & $97.57 \pm 1.96^{\mathrm{a}}$ & 0.000 & $84.63 \pm 8.08$ & $94.93 \pm 6.52^{\mathrm{a}}$ & 0.006 \\
\hline $\mathrm{P} / \mathrm{F}(\mathrm{mmHg})$ & $81.62 \pm 22.36$ & $145.83 \pm 26.86^{\mathrm{a}}$ & 0.000 & $78.22 \pm 24.28$ & $167.98 \pm 36.85^{a}$ & 0.000 & $77.54 \pm 24.69$ & $155.83 \pm 50.85^{a}$ & 0.000 \\
\hline $\mathrm{Cr}\left(\mathrm{ml} / \mathrm{cmH}_{2} \mathrm{O}\right)$ & $13.34 \pm 3.66$ & $24.26 \pm 8.00^{a}$ & 0.001 & $12.88 \pm 3.20$ & $27.51 \pm 7.99^{a}$ & 0.000 & $13.01 \pm 3.09$ & $26.67 \pm 8.60^{a}$ & 0.000 \\
\hline $\mathrm{HCO}_{3}{ }^{-}(\mathrm{mmol} / \mathrm{L})$ & $24.13 \pm 2.99$ & $23.02 \pm 3.25$ & 0.437 & $24.8 \pm 3.73$ & $22.08 \pm 3.79$ & 0.144 & $25.01 \pm 3.33$ & $22.54 \pm 3.90$ & 0.148 \\
\hline
\end{tabular}

$H R$ heart rate; MAP mean arterial pressure; $C V P$ central venous pressure $P A W P$ pulmonary artery wedge pressure; $C O$ cardiac output; $P a C O_{2}$ partial pressure of arterial carbon dioxide; $\mathrm{PaO}_{2}$ partial pressure of arterial oxygen; $\mathrm{SaO}_{2}$ arterial oxygen saturation; $P / F$ ratio of partial pressure of arterial oxygen to fraction of inspired oxygen; $\mathrm{Cr}$ respiratory system compliance; SI sustained inflation; IP increments of PEEP; PCV pressure-controlled ventilation;

${ }^{a}<0.05$ versus Before 


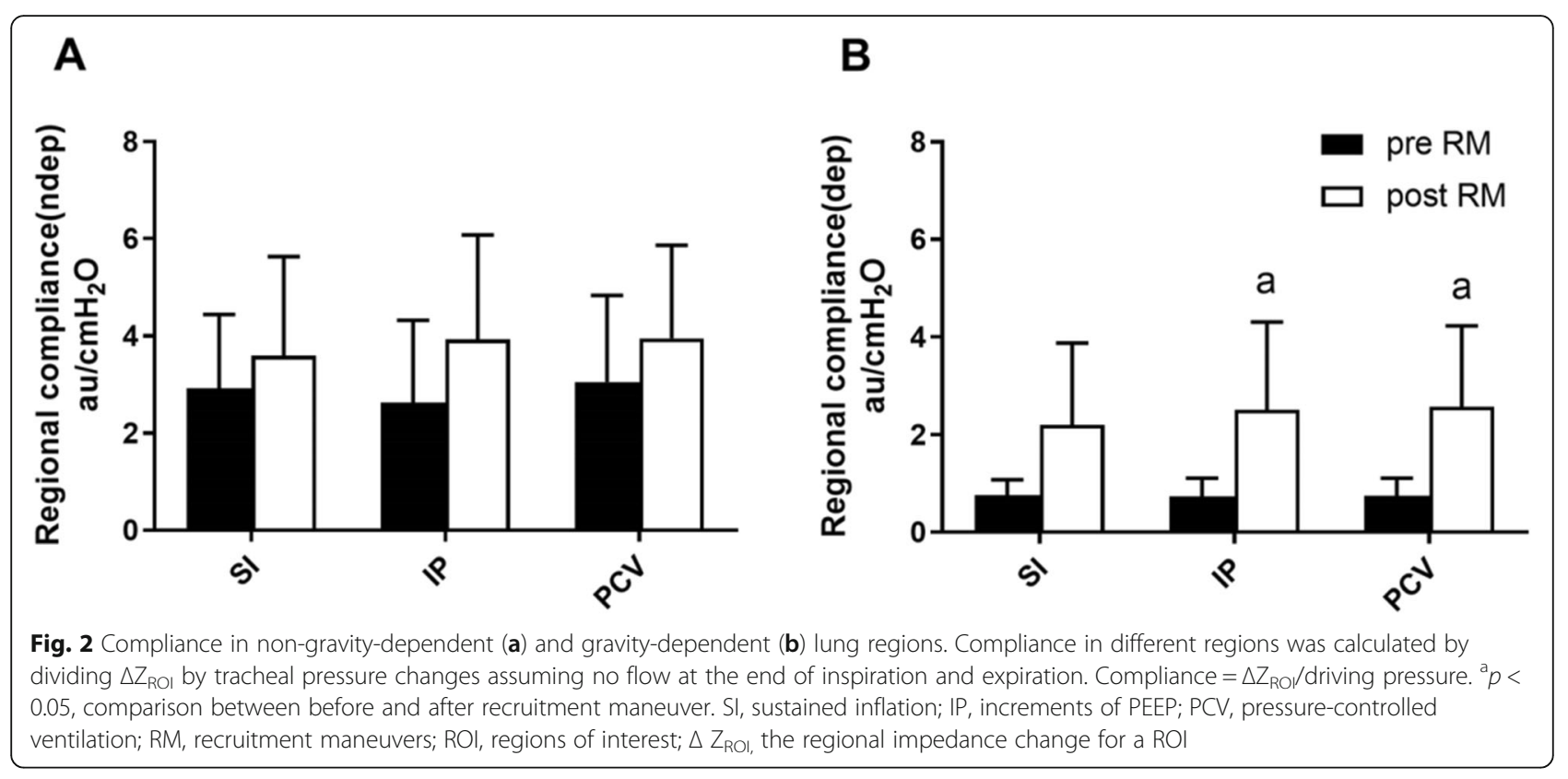

Patients with ARDS can suffer from inhomogeneous gas distribution, which leads to ventilation-perfusion mismatching, a high dead-space fraction, and the potential for ventilator-induced lung injury (VILI). Recruitment maneuvers aim to open collapsed alveoli and improve oxygenation and respiratory system compliance. However, recruitment maneuvers can over-distend aerated alveoli, and ventilation at high inflation pressures can lead to VILI.

Heterogeneous lung structure (i.e, collapsed and overexpanded contiguous lung regions) is increasingly recognized as a key risk factor for inhomogeneous gas distribution, VILI, and mortality in mechanically ventilated patients [20]. Recent studies showed that the extent of lung inhomogeneities increase with the severity of ARDS [21], and a protective ventilatory strategy may not be sufficient to minimize VILI in patients with ARDS whose disease process is characterized by an inhomogeneous distribution of pulmonary lesions that includes a small, nondependent, normally aerated compartment and a large, dependent, nonaerated compartment [22, 23].

In the present study, the inhomogeneous distribution of lung alterations in the pig model of ARDS was directly assessed using EIT. EIT has several advantages compared to established imaging techniques such as computed tomography as it is radiation free and applicable at the bedside; however, computation of the global inhomogeneity index is not a bedside technique as it requires offline measurements. In previous studies, Zhao [17] et al. developed the global inhomogeneity index to quantify the spatial extent and dispersion in the
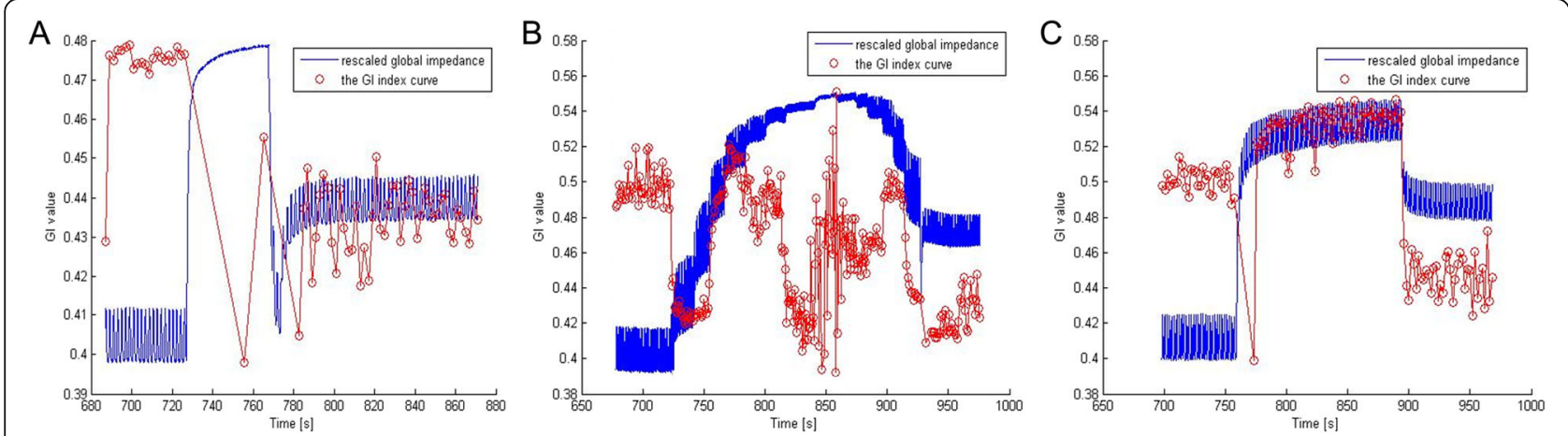

Fig. 3 EIT-based global inhomogeneity index with recruitment A: SI; B: IP; C: PCV. Recruitment maneuvers were performed in the same pig. The figure was exported by a data analysis tool, and the scales cannot be adjusted. Blue lines indicate rescaled global impedance, and red circles indicate the global inhomogeneity index. The global inhomogeneity index increased during recruitment with PCV, and varied during recruitment with SI and IP. The global inhomogeneity index was significantly decreased after recruitment with SI, IP, or PCV. SI, sustained inflation; IP, increments of PEEP; PCV, pressure-controlled ventilation; Gl, global inhomogeneity 


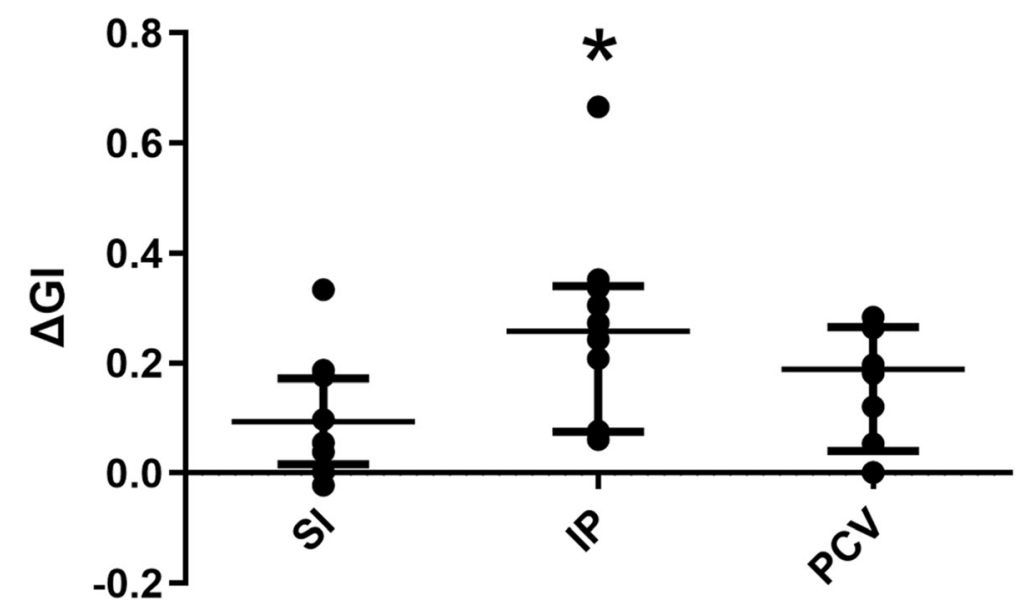

Fig. 4 Decrease in EIT-based global inhomogeneity index $(\Delta G \mid)$ after recruitment. ${ }^{*} p<0.05$ SI vs. IP

distribution of tidal breath, reporting that a larger global inhomogeneity index reflected more inhomogeneity between lung units. A tidal EIT image is generated and variations in pixel values are used as an indicator of the inhomogeneity of air distribution during tidal ventilation [17]. In the present study, we used the global inhomogeneity index as a direct representation of global inhomogeneity in tidal ventilation in ARDS pigs. As the global inhomogeneity index is $0.40 \pm 0.05$ in patients under anesthesia without pulmonary disease [17], the global inhomogeneity index was expected to be $>0.45$ in our experimental animals. We assessed the change in inhomogeneity with various recruitment maneuvers. Previous studies have shown different recruitment maneuvers are associated with differences in oxygenation, respiratory system compliance, hyperinflation, and hemodynamics [13, 24-26]. However, a ventilation strategy with aggressive lung recruitment may increase mortality in patients with ARDS [27]. The present study showed that increments of PEEP significantly improved inhomogeneity of the lung compared to sustained inflation in ARDS pigs, while there was no difference between increments of PEEP and PCV or between sustained inflation and PCV. These data suggest that evaluating the effect of recruitment maneuvers with EIT could play a role in minimizing VILI. Results of this study should be extrapolated to the clinical setting with caution, considering the differences in the shape of the thorax between pigs and humans. Clinical trials are required to evaluate the efficacy and safety of recruitment maneuvers in patients with ARDS, and current evidence does not support the use of recruitment maneuvers in clinical practice.

Our study was associated with several limitations. First, we measured hemodynamic parameters after not during recruitment maneuvers. A previous study [19] recorded hemodynamic parameters during and after recruitment maneuvers. Cardiac output was transiently decreased during recruitment maneuvers, there were no sustained hemodynamic effects following recruitment maneuvers, and no difference was found among recruitment maneuvers, which was consistent with our research. Second, the relative impedance changes monitored by EIT may have been affected by cardiac movement. Errors in the reconstruction algorithm and resorption atelectasis could not be measured as EIT was used for monitoring dynamic ventilation distribution. Third, the decrease in global inhomogeneity index in the different ROIs would be very informative. Unfortunately, our analytical software can only generate a global value. Last, maximal recruitment of the lung was not achieved with any maneuver. Failure to achieve maximal recruitment of the lung would affect monitoring of endexpiratory lung impedance. A peek pressure of 40 $\mathrm{cmH}_{2} \mathrm{O}$ may not have been sufficient for opening certain alveoli in ARDS pigs. Borges [28] et al. reported that when PEEP was set to $25 \mathrm{~cm} \mathrm{H}_{2} \mathrm{O}$ in patients with ARDS, producing peak airway pressures of $40 \mathrm{~cm} \mathrm{H}_{2} \mathrm{O}$, lung recruitment was approximately $67 \%$. When peak airway pressures of $60 \mathrm{~cm} \mathrm{H}_{2} \mathrm{O}$ were reached, lung recruitment was approximately $87 \%$. Maximal recruitment would further improve the heterogeneity of the lung, but with a concrete risk of damaging the nondependent normally aerated compartments.

\section{Conclusions}

This study used EIT to show that different recruitment maneuvers that achieve the same maximum pressure, including sustained inflation, increments of PEEP, and PCV, increased oxygenation and overall and EIT- estimated regional compliance, and decreased inhomogeneous gas distribution. Increments of PEEP significantly improved inhomogeneity of the lung compared to 
sustained inflation and PCV. Further studies are needed to confirm the clinical significance of these findings.

\section{Supplementary information}

Supplementary information accompanies this paper at https://doi.org/10. 1186/s12871-020-01164-X.

Additional file 1. Schematic diagram of ElT image partitioning.

\section{Abbreviations}

ARDS: Acute respiratory distress syndrome; EIT: Electrical impedance tomography; $\mathrm{PaO} 2$ : Arterial partial pressure of oxygen; FiO2: Fraction of inspired oxygen; P/F ratio: Arterial partial pressure of oxygen /fraction of inspired oxygen; PEEP: Positive end-expiratory pressure; PCV: Pressurecontrolled ventilation; $\Delta \mathrm{Gl}$ : Decrease in global inhomogeneity index; MAP: Mean arterial pressure; Vt: Tidal volume; I:E: Inspiration-to-expiration time ratio; CVP: Central venous pressure; PAWP: Pulmonary arterial wedge pressure; PiCCO: Pulse contour cardiac output; $T_{\text {Baseline: Time of baseline; }}$ $\mathrm{T}_{\text {ARDS: }}$ : Time of the ARDS model remained stable for $30 \mathrm{~min}$; CPAP: Continuous positive airway pressure; ECG: Electrocardiogram; ROI: Regions of interests; VILI: Ventilator-induced lung injury

\section{Acknowledgments}

We thank the Critical Care Institute for Laboratory Animal Science, Southeast University School of Medicine, Nanjing, namely Prof. Songqiao Liu, Dr. Qing Sun and Li Tan. We thank Prof. Songqiao Liu for his financial support. We thank Dr. Zhao PhD for providing the customized software.

\section{Authors' contributions}

XFP was responsible for conception and design of the study; acquisition, analysis and interpretation of data; and drafting and revising the article for final approval before publication. PC and WLH was responsible for design of the study; acquisition and analysis of data; and revising the article. $L L$ and LSQ participated in data analysis and interpretation of the results. GFM participated in interpretation of the results and writing the article. YY participated in data analysis; interpretation of the results; and writing the article. HYZ was responsible for the conception and design of the study; analysis and interpretation of data; drafting and revising the article, providing important intellectual content; and final approval before publication. All authors read and approved the manuscript.

\section{Funding}

A grant $(81370180,81971812$, Beijing, China) from the National Natural Science Foundation of China. The funding bodies had no role in the design of the study and collection, analysis, and interpretation of data and in writing the manuscript.

\section{Availability of data and materials}

The datasets used during the current study are available from the corresponding author on reasonable request.

\section{Ethics approval and consent to participate}

The study was approved by the Science and Technological Committee and the Animal Use and Care Committee of the Southeast University School of Medicine, Nanjing, China.

\section{Consent for publication}

Not applicable.

\section{Competing interests}

The authors declare that they have no competing interests.

Received: 4 January 2020 Accepted: 16 September 2020 Published online: 21 October 2020

\section{References}

1. Ashbaugh DG, Bigelow DB, Petty $T L$, Levine BE. Acute respiratory distress in adults. Lancet. 1967;2:319-23.
2. Gattinoni L, Mascheroni D, Torresin A, Marcolin R, Fumagalli R, Vesconi S, et al. Morphological response to positive end expiratory pressure in acute respiratory failure. Computerized tomography study. Intensive Care Med. 1986;12:137-42.

3. Pelosi P, D'Andrea L, Vitale G, Pesenti A, Gattinoni L. Vertical gradient of regional lung inflation in adult respiratory distress syndrome. Am J Respir Crit Care Med. 1994;149:8-13.

4. Bellani G, Laffey JG, Pham T, Fan E, Brochard L, Esteban A, et al. Epidemiology, patterns of care, and mortality for patients with acute respiratory distress syndrome in intensive care units in 50 countries. JAMA. 2016:315:788-800.

5. Meier T, Luepschen H, Karsten J, Leibecke T, Grossherr M, Gehring H, et al. Assessment of regional lung recruitment and derecruitment during a PEEP trial based on electrical impedance tomography. Intensive Care Med. 2008; 34:543-50.

6. Iannuzzi M, De Sio A, De Robertis E, Piazza O, Servillo G, Tufano R. Different patterns of lung recruitment maneuvers in primary acute respiratory distress syndrome: effects on oxygenation and central hemodynamics. Minerva Anestesiol. 2010;76:692-8.

7. Frerichs I. Electrical impedance tomography (EIT) in applications related to lung and ventilation: a review of experimental and clinical activities. Physiol Meas. 2000;21:R1-21.

8. Nopp P, Rapp E, Pfützner H, Nakesch H, Ruhsam C. Dielectric properties of lung tissue as a function of air content. Phys Med Biol. 1993;38:699-16.

9. Domenighetti G, Maggiorini M. Electrical impedance tomography to guide ventilation in ALI-ARDS patients: a research tool for zealous physiologists or an imminent support for the real world intensivist? Minerva Anestesiol. 2010:76:986-8.

10. Zhao Z, Pulletz S, Frerichs I, Müller-Lisse U, Möller K. The EIT-based global inhomogeneity index is highly correlated with regional lung opening in patients with acute respiratory distress syndrome. BMC Res Notes. 2014;7: 82-8

11. Garber JC. Guide for the Care and Use of Laboratory Animals. National Research Council (US) Committee for the Update of the Guide for the Care and Use of Laboratory Animals. 8th ed. US: National Academies Press; 2011.

12. National Research Council (NRC). Nutrition Requirements of Swine. 11th ed. Washington, DC: National Academy Press; 2012.

13. Odenstedt $\mathrm{H}$, Lindgren S, Olegård C, Erlandsson K, Lethvall S, Aneman A, et al. Slow moderate pressure recruitment maneuver minimizes negative circulatory and lung mechanic side effects: evaluation of recruitment maneuvers using electric impedance tomography. Intensive Care Med. 2005;31:1706-14.

14. David M, Karmrodt J, Bletz C, David S, Herweling A, Kauczor HU, et al. Analysis of atelectasis, ventilated, and hyperinflated lung during mechanical ventilation by dynamic CT. Chest. 2005;128:3757-70.

15. van der Burg PS, Miedema M, de Jongh FH, Frerichs I, van Kaam AH. Crosssectional changes in lung volume measured by electrical impedance tomography are representative for the whole lung in ventilated preterm infants. Crit Care Med. 2014:42:1524-30.

16. Mauri T, Bellani G, Confalonieri A, Tagliabue P, Turella M, Coppadoro A, et al. Topographic distribution of tidal ventilation in acute respiratory distress syndrome: effects of positive end-expiratory pressure and pressure support. Crit Care Med. 2013:41:1664-73.

17. Costa E, Borges JB, Melo A, Suarez-Sipmann F, Toufen C, Bohm SH, et al. Bedside estimation of recruitable alveolar collapse and hyperdistension by electrical impedance tomography. Intensive Care Med. 2009;35:1132-7.

18. Zhao Z, Möller K, Steinmann D, Frerichs I, Guttmann J. Evaluation of an electrical impedance tomography-based global inhomogeneity index for pulmonary ventilation distribution. Intensive Care Med. 2009;35:1900-6.

19. Lim SC, Adams AB, Simonson DA, Dries DJ, Broccard AF, Hotchkiss JR, Marini JJ. Transient hemodynamic effects of recruitment maneuvers in three experimental models of acute lung injury. Crit Care Med. 2004:32:2378-84.

20. Mead J, Takishima T, Leith D. Stress distribution in lungs: a model of pulmonary elasticity. J Appl Physiol. 1970;28:596-608.

21. Cressoni M, Cadringher P, Chiurazzi C, Amini M, Gallazzi E, Marino A, et al. Lung inhomogeneity in patients with acute respiratory distress syndrome. Am J Respir Crit Care Med. 2014;189:149-58

22. Bellani G, Guerra L, Musch G, Zanella A, Patroniti N, Mauri T, et al. Lung regional metabolic activity and gas volume changes induced by tidal ventilation in patients with acute lung injury. Am J Respir Crit Care Med. 2011;183:1193-9. 
23. Terragni PP, Rosboch G, Tealdi A, Corno E, Menaldo E, Davini O, et al. Tidal hyperinflation during low tidal volume ventilation in acute respiratory distress syndrome. Am J Respir Crit Care Med. 2007;175:160-6.

24. Santos RS, Moraes L, Samary CS, Santos CL, Ramos MB, Vasconcellos AP, et al. Fast versus slow recruitment maneuver at different degrees of acute lung inflammation induced by experimental sepsis. Anesth Analg. 2016;122: 1089-100

25. Richard JC, Maggiore SM, Jonson B, Mancebo J, Lemaire F, Brochard L. Influence of tidal volume on alveolar recruitment respective role of peep and a recruitment aneuver. Am J Respir Crit Care Med. 2001;163:1609-13.

26. Kheir JN, Walsh BK, Smallwood CD, Rettig JS, Thompson JE, Gómez-Laberge C, et al. Comparison of 2 lung recruitment strategies in children with acute lung injury. Respir Care. 2013;58:1280-90.

27. Cavalcanti $A B$, Suzumura ÉA, Laranjeira LN, Paisani DM, Damiani LP, Guimarães HP, et al. Effect of lung recruitment and titrated positive endexpiratory pressure (PEEP) vs low PEEP on mortality in patients with acute respiratory distress syndrome: a randomized clinical trial. JAMA. 2017;318: $1335-45$.

28. Borges JB, Okamoto VN, Matos GF, Caramez MP, Arantes PR, Barros F, et al. Reversibility of lung collapse and hypoxemia in early acute respiratory distress syndrome. Am J Respir Crit Care Med. 2006;174:268-27.

\section{Publisher's Note}

Springer Nature remains neutral with regard to jurisdictional claims in published maps and institutional affiliations.

Ready to submit your research? Choose BMC and benefit from:

- fast, convenient online submission

- thorough peer review by experienced researchers in your field

- rapid publication on acceptance

- support for research data, including large and complex data types

- gold Open Access which fosters wider collaboration and increased citations

- maximum visibility for your research: over $100 \mathrm{M}$ website views per year

At $\mathrm{BMC}$, research is always in progress.

Learn more biomedcentral.com/submissions 